\title{
MJN ASSESSMENT OF CHILDREN WORKING IN AGRICULTURE SECTORS ON THEIR KNOWLEDGE, ATTITUDE, AND PRACTICE REGARDING PESTICIDE HAZARDS AT VILLAGES IN ISMAILIA GOVERNORATE, EGYPT
}

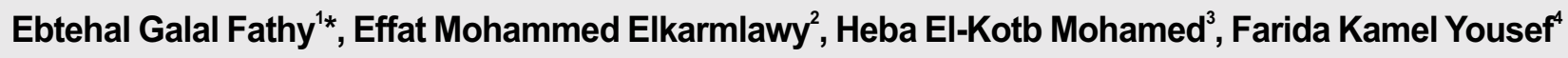 \\ ${ }^{1}$ Family and Community Health Nursing, Faculty of Nursing, Suez Canal University, Egypt \\ ${ }^{2}$ Community Health Nursing, Faculty of Nursing, Cairo University, Egypt \\ ${ }^{3}$ Family and Community Health Nursing, Faculty of Nursing, Suez Canal University, Egypt \\ ${ }^{4}$ Family and Community Health Nursing, Faculty of Nursing, Suez Canal University, Egypt \\ *Corresponding Author's Email: Ebtehalgalal882@gmail.com
}

\begin{abstract}
The agricultural sector represents the highest percentage of child laborers in Egypt. Children of poor rural families work in farms to increase a household's income. Aim: To assess knowledge, attitude, and practice of children working in agriculture sector about pesticide hazards. Methodology: Descriptive design was used in this study. The study sample includes 97 preparatory school students performing agricultural work from different educational grade. Tools: Tool (1): Children working in agriculture' structured interview questionnaire. Tool (2): An observational checklist measures child wearing personal protective equipment's (PPEs). Results: All children have inadequate knowledge, negative attitude, poor practice, and poor first aid practice. More than half of children wear protective boots and gloves, but more than three-quarters does not wear glasses or goggles. Conclusion: There was no statistically significant correlation between total scores of knowledge, practice and attitude of the studied group. Recommendations: Organizing workshops and school activities such as drama plays, painting, and games about pesticides and their dangers with each agricultural cycle in schools located in rural areas can be effective.
\end{abstract}

Keywords: Attitude, Children working in agriculture, Knowledge, Pesticides, Practice

\section{INTRODUCTION}

The pesticide is a substance or mixture of chemicals which is for preventing, destroying, or dominant any agent as well as vectors of human or animal diseases, unwanted species of plants or animals. Exposure to pesticides through various routes (e.g., residues in food and drinking water) lead to hazards range from shortterm (e.g., skin and eye irritation, headaches, dizziness, and nausea) to chronic impacts (e.g., cancer, asthma, and diabetes) (Vryzas, 2018).

The Health Belief Model, a model that predicts behavior from a perceived threat to a disease combined with barriers and benefits of recommended action, may facilitate understanding of the cognitive factors important to perform these behaviors. We adapted the Health Belief Model and incorporated additional factors to examine the importance of beliefs, occupational characteristics, and an attribute of the worksite to farmworkers' engagement in pesticide safety practices (Yazdanpanah et al., 2016).

Significant of the study

Pesticides are a significant source of mortality and morbidity worldwide, especially in developing countries where economies are heavily reliant on agriculture. According to the World Health Organization, 2 to 5 million cases of poisonings per year by pesticides worldwide are recorded, among which 300000 cases have resulted in death (Vikkey et al., 2017).

\section{METHODOLOGY}

This study aimed to assess knowledge, attitude, and practice of pesticide use among children working in 
agricultural field.

Research design: Descriptive design was used.

\section{Setting}

This study was conducted at Al Qassasin Al Kadima preparatory school, in rural areas in the district and city of Al Qassasin El Jadida. Al Qassasin El Jadida's city includes many villages and lies in the west of Ismailia governorate on the Suez Canal in Egypt. This school is selected randomly from 5 high capacity schools that were selected randomly from 25 preparatory schools affiliated to Al Qassasin Educational Administration.

\section{Subjects}

Convenient sample consists of preparatory school students working in agriculture from different educational grades. The study sample was selected based on the following inclusion criteria: parent's consent to the child's participation in the study, the child must be enrolled at the school during the collection of the sample, the child should work in agriculture fields besides the school.

Exclusion criteria: The child misses a lot and is not regular at school.

Sample size: 97 students participated in the study, it was determined according to the following equation (Wassertheil-Smoller, 2004)

Sample size $=(\mathrm{Za}) 2 *(\mathrm{~S}) 2 / \mathrm{d} 2=(1.96) 2 *(1.6) 2 / 0,1=$ 97 students.

\section{Tools for data collection}

Tool (1): Children working in Agricultural Fields were given Structured Interviewing Questionnaire: used to assess knowledge, attitude, practice. It is divided into the following six parts:

a) Part I: Socio-demographic characteristics: it composed of 3 closed-ended questions; age, sex, educational grade.

b) Part II: Knowledge regarding pesticide: It is formed of 12 multiple-choice questions about types of pesticides used, source of pesticide knowledge, route of pesticide entry into the human body, etc.

Scoring system: the scores ranged between zero ( 0 ) for incorrect answers and one (1) for correct answers. The total scores of all questions categorized into two levels: $<50 \%$ inadequate knowledge and $\geq 50 \%$ adequate knowledge (Norkaew et al., 2010). c) Part III: Attitude regarding pesticide based on the health belief model

It composed of 27 close-ended questions about perceived susceptibility, perceived severity, perceived benefits, perceived barriers, cues to action, and selfefficacy (Suratman et al., 2016).

Scoring system: It categorized into two levels for the Health Belief Model as follow: each positive-direction scored as "Agree" $=3$, "Neutral" $=2$, "Disagree" $=1$ and Negative-direction scored as "Agree" $=1$, "Neutral" $=2$, "Disagree"=3

The positive statement can lead children to follow healthy behavior. But negative statement aimed at a belief, which may inhibit children to practice healthy behavior. The total scores of positive statements were 39 degrees for 13 statements, and the total scores of negative statements were 42 for 14 statements.

d) Part (IV): Assessment of reported-pesticide practice: It composed of 26 multiple-choice closedended questions about mixing pesticides, spraying pesticides, storing pesticides, personal hygiene and cleaning the tools after mixing or spraying, disposal of pesticides container and pre-harvest period.

\section{Scoring system}

It scored as follows, "Done correctly"=1"Done incorrectly" $=0$

The total scores categorized into three levels as good scores were $\geq 75 \%$, average scores were $\leq 50 \%$ to less than $75 \%$, and poor scores were less than $50 \%$ (Norkaew et al., 2010).

e) Part (V): Self-reported toxicity symptoms of pesticide: used to assess the presence of toxicity symptoms as in the nervous system, eyes, respiratory system, dermatological and muscles, gastrointestinal system.

Scoring System: it is scored as follow: when reported symptoms $=" 1 "$ and if no reported symptoms $=" 0 "$.

f) Part (VI): Reported first aid practice for pesticide poisoning it included questions about first aid in cases of pesticide enters eyes, spill on clothes or skin, swallowing of pesticide, inhalation of pesticide.

Scoring system: it scored as follows: "Done correctly" $=1$ when performing first aid and "Done incorrectly" $=0$ when not perform first aid. 
The second tool: An observational checklist: it is used to assess children for PPE it includes 5 items such as overall uniform, head cover, eye goggles, gloves, protective apron, safety boots, and a respiratory mask.

Scoring system: it scored as "Done"=1 for using PPE and "Not done" $=0$ for don't use PPE.

\section{Testing validity}

Tools of data collection were tested for content validity by a panel of five experts in the field of community health nursing, faculties of nursing at Cairo University and Suez Canal University. Modifications were done according to the experts' opinions.

\section{Content Reliability}

The reliability of the tools was done by using (test and retest) measurement and applied time to be sure the consistency of answers. The reliability was assured using Cronbach's alpha; it indicated that the tool has a reliability of 0.925 .

\section{Pilot study}

It was conducted on $10 \%$ of subjects to test whether tools of data collection are clear, understandable, feasible and valid. Modification of tools including rewarding or omissions was done.

\section{Fieldwork}

Data collection was carried out in the period from October 2017 to April 2018. After making the tool ready, the study sample was recruited. A questionnaire was administered to the sample to assess the existing level of knowledge, attitude, and practice. Data was collected from the students during breaks time through the school day at the social worker's room, library, garden, etc. The school was visited two days on Monday from 8 am to 1 pm and Tuesday from 8 am to 11 am every week.

The researcher interviewed students face to face after introducing herself and explaining the aim of the study. During the interview, the researcher answers questions on the data collection sheet from the students. Each sheet lasted about 30 minutes to be filled.

During the study assessment, accurate observation has been done for children workers in the farmland on vacation days to observe applying PPE during their work in farmland; the suitable days were Friday, Sunday every week, and public holidays.

\section{Ethical considerations}

Informed consent was obtained from parent's children after explaining the study's purpose, no harmful methodology was used with the participant; they had the right to withdraw from the study at any time.

\section{Statistics Analysis}

Data were analyzed using the IBM SPSS software package. Qualitative data were described using the number and percent. Quantitative data were described using the range, mean, and standard deviation. The significance of the obtained results was judged at the $5 \%$ level. The used tests were:

1 - ANOVA with repeated measures: For normally distributed quantitative variables, to compare between more than two periods or stages

2 -Friedman test: For abnormally distributed quantitative variables, to compare between more than two periods or stages.

\section{RESULTS}

Table 1: Distribution of the children working in agricultural fields according to their sociodemographic characteristics $(n=97)$

\begin{tabular}{|c|c|c|}
\hline Socio-demographic characteristics & No. & $\%$ \\
\hline Age (years) & & \\
\hline$<14$ & 37 & 38.1 \\
\hline$\geq 14$ & 60 & 61.9 \\
\hline Min.-Max. & \multicolumn{2}{|c|}{$13.0-15.0$} \\
\hline Mean \pm SD. & $13.93 \pm 0.83$ \\
\hline Family member working in agriculture & \multicolumn{2}{|c|}{$1.0-8.0$} \\
\hline Min.-Max. & \multicolumn{2}{|c|}{$3.34 \pm 1.59$} \\
\hline Mean \pm SD. & \multicolumn{2}{|c}{} \\
\hline
\end{tabular}

Tables 1 shows that the children's age ranged from 1315 years with a mean age was $13.93 \pm 0.83$ and about $1-8$ of family members were working in agriculture field with a mean $3.34 \pm 1.59$

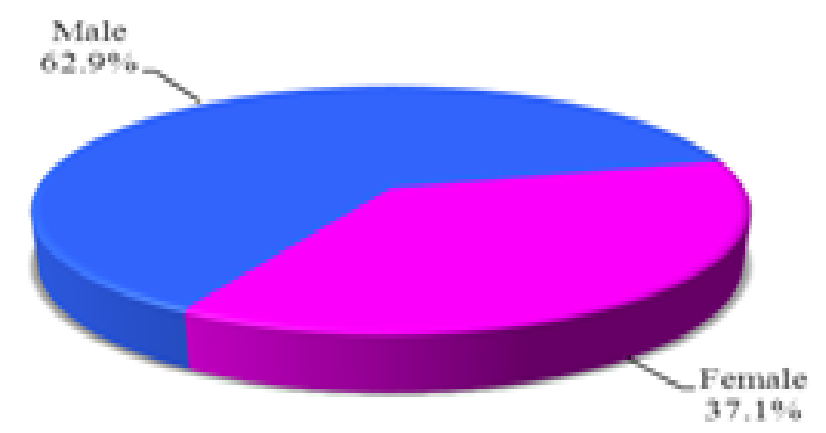

Figure 1: Distribution of the children working in agriculture according to sex 
Figure 1 illustrated that the almost of children working in agriculture were males $(62.9 \%)$, wherever $37.1 \%$ were females.

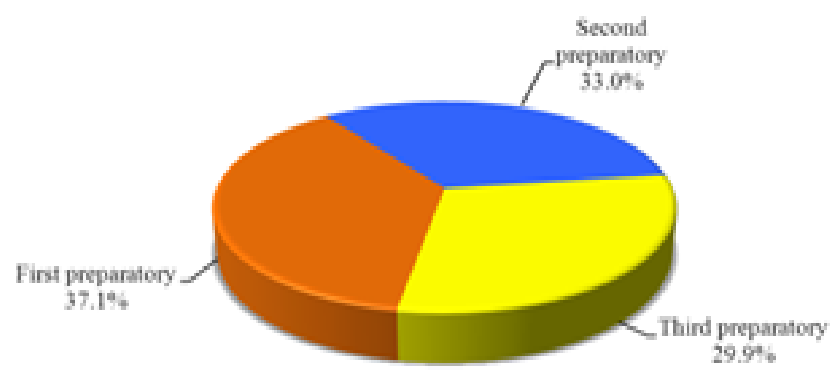

Figure 2: Distribution of the children working in agriculture according to their grades

Figure 2 presents that $37.1 \%$ of children working in agriculture field were in the first preparatory grade and $33 \%$ of them were in the second preparatory grade.

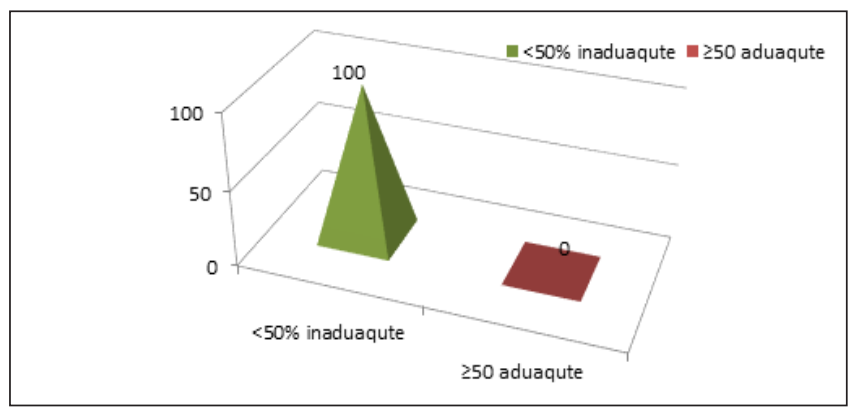

Figure 3: Distribution of the children working in agriculture according to the mean of a total score of knowledge

Figure 3 indicates that $100 \%$ of children had inadequate knowledge and none of them had adequate knowledge.

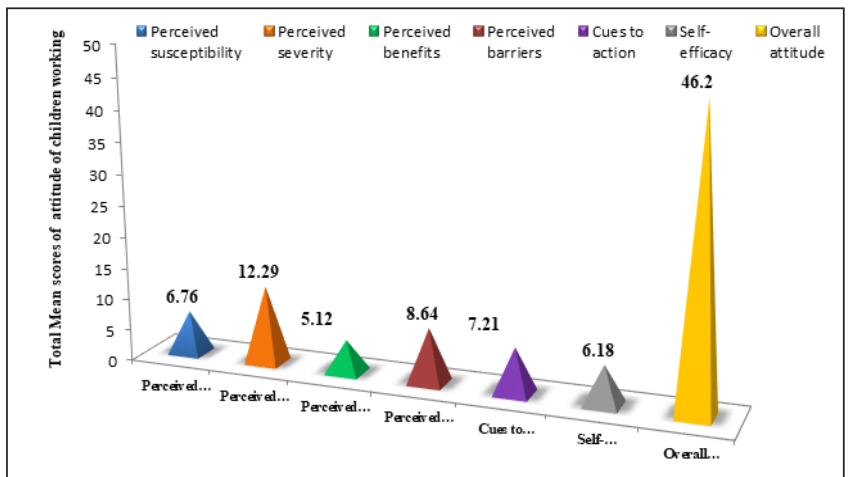

Figure 4: Distribution of the children working in agricultural according to their total mean scores of attitudes about pesticide hazards and safety procedures using the health belief model
Figure 4 indicates that children's perceived susceptibility was 6.76 , perceived severity was 12.29 , a perceived benefit was 5.12. Also, the perceived barrier was 8.64 , cues to action were 7.21 , and self-efficacy was 6.18 , but their overall attitude was 46.2 .

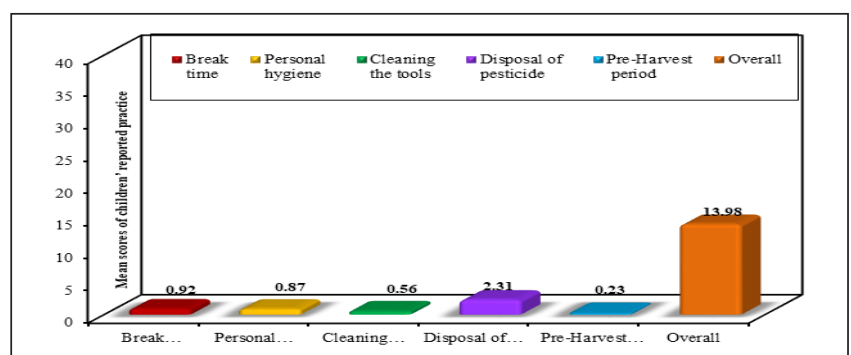

Figure 5: Distribution of the children working in agriculture according to the mean scores of their reported practice about the applications of pesticides

Figure 5 shows that mean scores for mixing pesticides equally (4.22), spraying pesticides equally (3.42), storing pesticides (1.46), break time equally (0.92), personal hygiene equally (0.87), cleaning the tools (0.56), disposal pesticides (2.31), pre-harvest period $(0.23)$, and their overall practice was 13.98 .

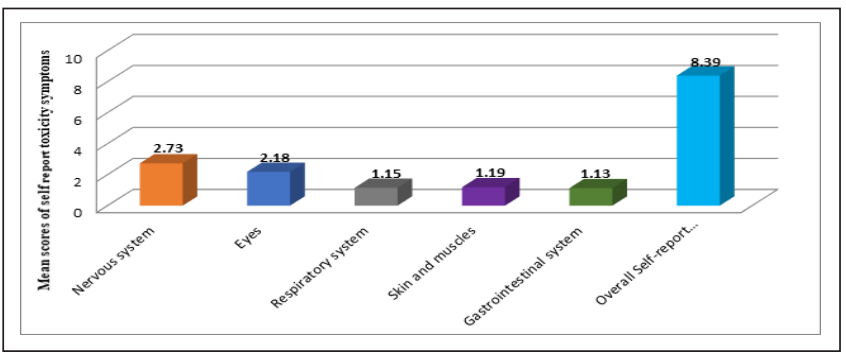

Figure 6: Distribution of the children working in agricultural field according to their mean scores of selfreport toxicity symptoms

Figure 6 reveals that the mean scores of overall toxicity symptoms were (8.39), and for nervous symptoms, eyes, respiratory system, skin and muscles, and gastrointestinal system were $2.73,2.18,1.15,1.19$, 1.13 equally.

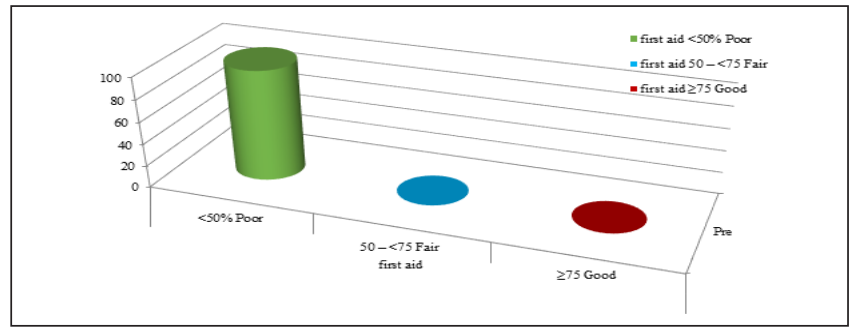

Figure 7: Distribution of the children working in agriculture according to their first aids' reported practice in cases of poisoning with pesticide 
Figure 7 shows that all children had poor first-aid practice, and none of them had fair or good first-aid practice in cases of poisoning with pesticide.

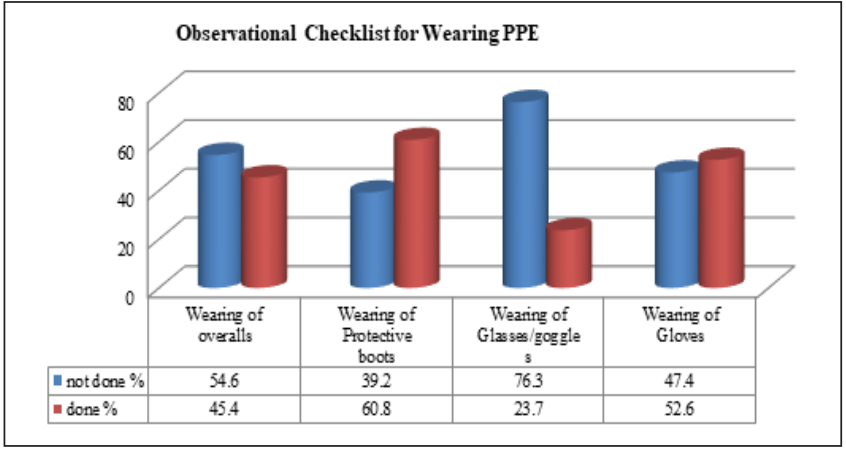

Figure 8: Distribution of the children working in agriculture according to wearing of PPE during spraying of pesticide.

Figure 8 indicates that $60.8 \%$ and $52.6 \%$ of children wore protective boots and gloves, but $76.3 \%$ of children did not wear glasses or goggles and $54.4 \%$ did not wear overalls during spraying of pesticide.

Table 3: Correlation between knowledge, practice, and attitude of children working in agriculture

\begin{tabular}{|l|c|c|}
\hline \multirow{2}{*}{ Knowledge VS practice } & $r$ & 0.131 \\
\cline { 2 - 3 } & $p$ & 0.202 \\
\hline \multirow{2}{*}{ Knowledge VS attitude } & $r$ & -0.131 \\
\cline { 2 - 3 } & $p$ & 0.202 \\
\hline \multirow{2}{*}{ Practice VS attitude } & $r$ & -0.111 \\
\cline { 2 - 3 } & $p$ & 0.280 \\
\hline
\end{tabular}

R: Pearson coefficient

P: $p$ value for Friedman test $*$ : Statistically significant at $p \leq 0.05$

Table 3 shows that there was no statistically significant correlation between total scores of knowledge, practice, and attitude of children working in agriculture.

\section{DISCUSSION}

The present study indicated that the current sample's age ranged from 13-15 years and they were males. This is consistent with the research of Öztaș et al., (2018) with a sample size of 420 seasonal agricultural employees in Turkey. They found that the majority of the farmers were males and applying pesticides between the ages of 9 and 15 years and 16 and 19 years.

From the researcher's point of view, the age of children working in agricultural field is one of the social and economic factors that affect their level of awareness. The children have limited experience and are less familiar with banned pesticides and their health risks to human health and the environment.

According to the total scores of knowledge of the current study, the majority of children have inadequate knowledge. Unlike, a study by Zhao et al., (2018) clarified most trained children showed higher levels of knowledge of pesticide use.

While, the research of Chen et al., (2016) in East China observed that only one-quarter of respondents had good scores of knowledge, while a few numbers at the poor level. Concerning the researcher's view, these findings was clarified by the lack of formal training or participation in an educational program on pesticides for children working in agriculture.

The total mean scores of attitudes were 46.2 in the current study. This is in line with a research of Corral et al., (2017) were consistent with Health Belief Model (HBM), persons must perceive themselves as susceptible to risk before they will take action. They suggest that perceived control, not perceived risk, leads to action.

This finding was supported by a survey in the Southern Islamic Republic of Iran conducted by Yazdanpanah et al., (2016) regarding Safe Use of Pesticides through HBM. Findings revealed that the model is suitable for predicting intention. Therefore, those farmers who received more cue to action perceived more severity and showed self-efficacy with greater intention to engage in safe behavior.

On the other hand, these results are disagreeing with research of Weng \& Black, (2015) about Taiwanese farmworkers' pesticide where it was found that the belief of wearing PPE when working with pesticides was not reflected in the clothing worn. Farmworkers indicating that PPE was uncomfortable may be one reason for inconsistency between the farmers' attitudes and what they wore. Concerning the researcher's point of view, children working in agricultural field who perceived non-usefulness of PPE were less likely to wear it. Also, unavailability, high price, lack of use by neighbors or colleagues, and ignorance of PPE in extension training, were the foremost necessary constraints in PPE use by children farmers.

According to the current study's practice revealed 
that mean scores for mixing pesticides practice equally (4.22). In congruence with these results, a study of Chakraborty et al., (2016) in their research in India revealed that majority of the farmworkers used pesticides in the recommended concentrations. Concerning the researcher's point of view, the higher level of education and awareness about hazards of pesticides on soils, crops, and environment among farm children workers may be one reason for the adherence to recommended concentrations, but beliefs may still exist that more pesticides are needed for successful crops.

Regarding tools and direction of spraying pesticides, the present study revealed that mean scores of spraying pesticides was 3.42. These findings are not consistent with a results of Corral et al., (2017) in the Coquimbo Region of Chile reported that almost all farmers used the available home utensils such as spoon, cup, or jar, while half of them used their hands to roughly estimate the dosage and mix pesticides. From researcher's point of view, children farmers were unaware of the safety precautions of pesticide poisoning and adequate use of pesticides to promote health and prevent environmental hazards. The current study's mean scores of pesticide's storages was 1.46.

On the same respect, among apple farmers (Bagheri et al., 2018) in Iran it was found that farmers store the pesticides in stalls and warehouses, while few numbers store the pesticides in their houses. Many of the farmers stated that they prepare the pesticide's sprays in the plantations or next to irrigation wells. From the researcher's point of view, children were unaware that transporting and storing chemical containers together with the food is extremely dangerous and causes contamination of food, poisoning, and collective effects.

On the other side, a survey by Houbraken et al., (2016) about pesticide knowledge and practice among horticultural workers in the Lâm Đồng region, Vietnam showed that chrysanthemum farmers stored pesticides in open storage rooms. Concerning the researcher's point of view, strawberry and chrysanthemum farmers try to minimize storage by only purchasing the number of pesticides that are needed for the application, which is a good solution for reducing the dangers of pesticides.

Concerning the current study, the mean scores of break time was 0.92 , personal hygiene 0.87 and cleaning the tools was 0.56 . These results were mismatching with Osborne et al., (2015). Their survey clarified only about more than one-third of the farmers take a shower after use and more than half changed their clothes after pesticide application work. But, more than one-third didn't wash the sprayer after use. From the researcher's point of view, children aren't well informed of taking shower after mixing or spraying pesticides that protect their bodies from dermatological side effects of pesticides, and not aware of washing machines and tools. They were also not aware of blockages of tools by dry pesticides solution which caused a malfunction in the spray machine.

In the current study, mean scores of disposal pesticides was 2.31 , pre-harvest period 0.23 . On the same line, a study by Bagheri et al., (2018) illustrated that nearly one-third reported that they dump the empty containers in the orchard fields and almost an equal proportion reported that they usually bury the empty containers. Hence, Houbraken et al., (2016) concluded that half of the pesticide packages are incinerated and more than one third be thrown away with the garbage/taken to the landfill. Only a small percentage disposes the packages into the local river.

As of the researcher point of view, children had a bad experience from their parents or neighborhood in the fields. They are not aware that empty container of pesticides causes harm and so, opportunities to safely discard and recycle empty containers should be developed to save the soils, fishes, birds and the atmosphere.

The present study showed that more than half of the children wore protective boots and gloves, but more than three-quarters of them did not wear glasses or goggles and more than half did not wear overalls. These results were consistent with a study by Gamble, (2018) in Canada that two-third of the farmers wore longsleeved shirts, almost two-thirds of them wore long trousers and wore glasses, half of them wore gloves, nearly one-third of them used masks, one-quarter of them used hats, few numbers of them wore overalls, boots, and aprons.

In contrast to the current study, a survey of 301 tomato farmers (Damalas \& Abdollahzadeh, 2016) indicated that most of the farmers' showed low frequency use of gloves, goggles, face mask, coveralls, and respirator. Also, a study of (Bagheri et al., 2018) indicated that most farmers used trousers, long-sleeved blouses/shirts, and gloves when spraying, but coveralls and goggles were rarely used. 
In the researcher's opinion, the children who work in agriculture did not wear PPE as face masks as they were uncomfortably to wear and wearing it for long periods caused sweating and difficulty in breathing. Uncomfortable environmental conditions and the cumbersome equipment cause the children to ignore the safety measurements, increasing the danger of poisoning. Regarding self-reported toxicity symptoms, the current results revealed that more than half of children working in agricultural fields experience headache, dizziness, excessive sweat, skin rash. More than one-third experience salivation, excessive urination, abdominal pain, fever, more than two-thirds had a burning sensation in eyes $\backslash$ face.

Corresponding with the current results, Van Wendel de Joode et al., (2016) conducted a cross-sectional study among 140 children living near banana plantations farms in the Talamanca County, in Costa Rica, indicated that exposure impaired visual-motor coordination, behavior, and color discrimination abilities in both girls and boys, and working memory in boys, children's verbal learning, poorer working memory IQ scores in school going children.

Furthermore, the results of Bondori et al., (2018) about the use of personal protective equipment towards pesticide exposure, farmers' attitudes and determinants of behavior in Iran showed that common symptoms among the farmworkers were skin rash, headache, excessive sweating, and diarrhea only. In the researcher's view, the children are less aware, less educated, and less experienced so they are more susceptible to pesticides. These pesticides are more toxic to their bodies, skin, and eyes leading to more toxic symptoms. This also leads to the absence of children from school, which affects their academic achievement and low IQ.

Regarding first aid, the current study indicated that the children have poor first aid practice. On the same line, a study of Nurmatov et al., (2018) showed that to cool the skin's burn caused by pesticides the affected area must be kept under cold running water for $20 \mathrm{~min}$. Then the clothing and jewelry must be removed, then the emergency services must be called and the skin burn must be covered with a sterile dressing or cloth and the patients must be kept warm.

On the contrary, in the research of Okumu et al.,
(2018) about acute poisonings at a regional referral hospital in Western Kenya it was clarified that sampled studied often used raw eggs or porridge to induce vomiting after exposure to these agents. This led to aspiration pneumonia, which further complicated the management of the cases. In the opinion of the researcher, poisoning with pesticides usually increases during the growing seasons of crops, especially the rice planting season, in the period from May to August of each year. Symptoms of poisoning often appear in farmers, their children who work in agricultural fields, and people who do not follow instructions when spraying pesticides and do not wear personal protective equipment. Therefore, they need to learn first aid practices to deal with such cases when pesticide poisoning.

The present study showed that there was no statistically significant correlation between total scores of knowledge, practice, and attitude of the studied group. Another study (Kalliora et al., 2018) in their research about pesticide exposure with human congenital abnormalities in Greece, indicated that the experience has shown significant influence of knowledge on the practice of farmworkers in which knowledge is positively associated with their experience whereas experience could not influence their practice much. In the researcher's opinion, children with a low level of education when using pesticides find it difficult to understand the instructions and safety procedures printed on the product labels as they are printed in English causing higher risk.

\section{CONCLUSION}

In light of the study findings, there was no statistically significant correlation between total knowledge, practice, and attitude of the studied group.

\section{RECOMMENDATIONS}

Based on the findings of the current study, the followings are recommended:

- Availability of books and handouts, containing all necessary information about pesticides and its hazards on humans and the environment at the school library.

- Using mass media, posters, and leaflets as tools for education about pesticides. 


\section{REFERENCES}

Bagheri, A., Emami, N., Allahyari, M. \& Damalas, C. (2018). Pesticide handling practices, health risks, and determinants of safety behavior among Iranian apple farmers. Human and Ecological Risk Assessment: An International Journal, 24(8), pp 2209-2223.

Bondori, A., Bagheri, A., Damalas, C. \& Allahyari, M. (2018). Use of personal protective equipment towards pesticide exposure: Farmers' attitudes and determinants of behavior. Science of The Total Environment, 639, pp 1156-1163.

Chakraborty, P., Khuman, S., Selvaraj, S., Sampath, S., Devi, N., Bang, J. \& Katsoyiannis, A. (2016). Polychlorinated biphenyls and organochlorine pesticides in River Brahmaputra from the outer Himalayan Range and River Hooghly emptying into the Bay of Bengal: Occurrence, sources and ecotoxicological risk assessment. Environmental Pollution, 219, pp 998-1006.

Chen, S., Gu, S., Wang, Y., Yao, Y., Wang, G., Jin, Y. \& Wu, Y. (2016). Exposure to pyrethroid pesticides and the risk of childhood brain tumors in East China. Environmental Pollution, 218, pp 1128-1134.

Corral, S., De Angel, V., Salas, N., Zúñiga-Venegas, L., Gaspar, P. \& Pancetti, F. (2017). Cognitive impairment in agricultural workers and nearby residents exposed to pesticides in the Coquimbo Region of Chile. Neurotoxicology and teratology, 62, pp13-19.

Damalas, C. \& Abdollahzadeh, G. (2016). Farmers' use of personal protective equipment during handling of plant protection products: Determinants of implementation. Science of The Total Environment, 571, pp 730-736.

Gamble, D. (2018). The chemistry component of agricultural pesticide regulatory technology. Current Opinion in Environmental Science \& Health, 4, pp 16-18.

Houbraken, M., Bauweraerts, I., Fevery, D., Van Labeke, M. \& Spanoghe, P. (2016). Pesticide knowledge and practice among horticultural workers in the Lâm Đồng region, Vietnam: A case study of chrysanthemum and strawberries. Science of The Total Environment, 550, pp 1001-1009.

Kalliora, C., Mamoulakis, C., Vasilopoulos, E., Stamatiades, G., Kalafati, L., Barouni, R., Karakousi, T., Abdollahi, M. $\&$ Tsatsakis, A. (2018). Association of pesticide exposure with human congenital abnormalities. Toxicology and Applied Pharmacology, 346, pp 58-75.

Norkaew, S., Siriwong, W., Siripattanakul, S. \& Robson, M. (2010). Knowledge, attitude, and practice (KAP) of using personal protective equipment (PPE) for chilli-growing farmers in Huarua Sub-District, Mueang District, Ubonrachathani Province, Thailand. Journal of Health Research, 24(2), pp 93-100.

Nurmatov, U., Mullen, S., Quinn-Scoggins, H., Mann, M. \& Kemp, A. (2018). The effectiveness and cost-effectiveness of first aid interventions for burns given to caregivers of children: A systematic review. Burns, 44(3), pp 512-523.

Okumu, M., Patel, M., Bhogayata, F., Olweny, I., Ochola, F. \& Onono, J. (2018). Acute Poisonings at a Regional Referral Hospital in Western Kenya. Tropical Medicine and Infectious Disease, 3(3), pp 96.

Osborne, P., Xu, Z., Swanson, K., Walker, T. \& Farmer, D. (2015). Dicamba and 2,4-D residues following applicator cleanout: A potential point source to the environment and worker exposure. Journal of the Air \& Waste Management Association, 65(9), pp 1153-1158.

Öztaş, D., Kurt, B., Koç, A., Akbaba, M. \& İlter, H. (2018). Knowledge Level, Attitude, and Behaviors of Farmers in Çukurova Region regarding the Use of Pesticides. BioMed Research International, 2018, pages 7.

Suratman, S., Ross, K., Babina, K. \& Edwards, J. (2016). The effectiveness of an educational intervention to improve knowledge and perceptions for reducing organophosphate pesticide exposure among indonesian and south australian migrant farmworkers. Risk management and healthcare policy, 9, pp 1-12.

Van Wendel De Joode, B., Mora, A., Lindh, C., Hernández-Bonilla, D., Córdoba, L., Wesseling, C., Hoppin, J. \& Mergler, D. (2016). Pesticide exposure and neurodevelopment in children aged 6-9 years from Talamanca, Costa Rica. Cortex, 85, pp 137-150.

Vikkey, H., Fidel, D., Elisabeth, Y., Hilaire, H., Hervé, L., Badirou, A., Alain, K., Parfait, H., Fabien, G. \& Benjamin, F. 
(2017). Risk Factors of Pesticide Poisoning and Pesticide Users' Cholinesterase Levels in Cotton Production Areas: Glazoué and Savè Townships, in Central Republic of Benin. Environmental Health Insights, 11.

Vryzas, Z. (2018). Pesticide fate in soil-sediment-water environment in relation to contamination preventing actions. Current Opinion in Environmental Science \& Health, 4, pp 5-9.

Wassertheil-Smoller, S. (2004). Biostatistics and Epidemiology. A Primer for Health and Biomedical Professionals, $3^{\text {rd }}$ Ed, Springer-Verlag, Springer Science, New York, 3, pp 153-158.

Weng, C. \& Black, C. (2015). Taiwanese farm workers' pesticide knowledge, attitudes, behaviors and clothing practices. International journal of environmental health research, 25(6), pp 685-696.

Yazdanpanah, M., Tavakoli, K. \& Marzban, A.(2016). Investigating Factors Influence Framers’ Intention Regarding Safe Use Of Pesticides Through Health Belief Model. Iranian Agricultural Extension and Education Journal, 11(2), pp 21-29.

Zhao, L., Wang, C., Gu, H. \& Yue, C.(2018). Market incentive, government regulation and the behavior of pesticide application of vegetable farmers in China. Food Control, 85, pp 308-317. 